\title{
Caso clínico-radiológico pediátrico
}

\author{
HERNÁN GARCÍA F.*, JOSÉ I. CANCINO V.*, ALEJANDO BUSTOS A.** y CRISTIÁN GARCÍA B.***
}

\section{Pediatric clinical-radiological case}

\section{Historia clínica}

Paciente de sexo masculino, 14 años. Consulta por deformación torácica.

Se solicita Radiografía (Rx) de tórax en proyecciones anteroposterior y lateral (Figura 1).

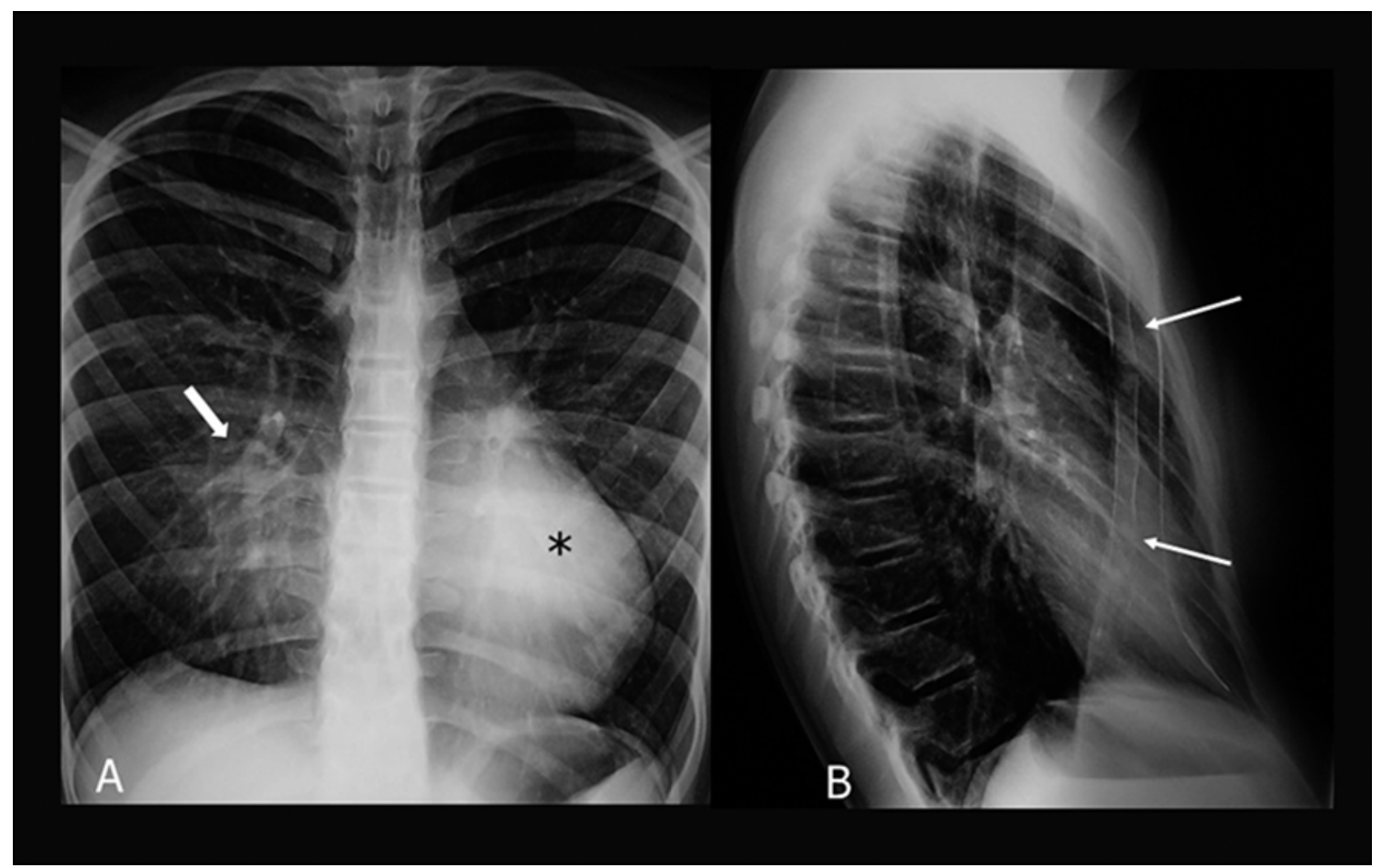

Figura 1. Radiografía de tórax en proyecciones anteroposterior y lateral.

\section{¿Cuál sería su diagnóstico? \\ ¿Solicitaría algún otro estudio de imágenes?}

* Interno $7^{\circ}$ Año, Facultad de Medicina, Pontificia Universidad Católica de Chile.

** Médico Radiólogo, Centro Radiológico del Lago, Villarrica, Región de La Araucanía, Chile.

*** Médico Radiólogo. Departamento de Radiología, Facultad de Medicina, Pontificia Universidad Católica de Chile. 


\section{Hallazgos Radiológicos}

Figura 1. Rx de tórax en proyecciones AP (A) y lateral (B) muestra acentuada depresión del esternón en su mitad inferior, especialmente evidente en la proyección lateral (flechas delgadas). En la proyección AP, esto determina horizontalización de los arcos costales anteriores, compresión y borramiento del contorno derecho del corazón (flecha gruesa) y una opacidad del lóbulo inferior del pulmón izquierdo $\left(^{*}\right)$ compatible con atelectasia secundaria. Todos estos hallazgos son compatibles con un pectus excavatum.

Como complemento, se solicitó tomografía computada de tórax (Figura 2). En un corte axial a nivel del apéndice xifoides del esternón, se observa marcado estrechamiento del diámetro AP del tórax, en la línea media. El índice de Haller, obtenido de la relación entre el diámetro transversal del tórax $(24,5 \mathrm{~cm})$ y la distancia entre el esternón y la columna vertebral en el punto de mayor depresión $(5,3 \mathrm{~cm})$ corresponde a 4,6, compatible con un pectus excavatum severo.

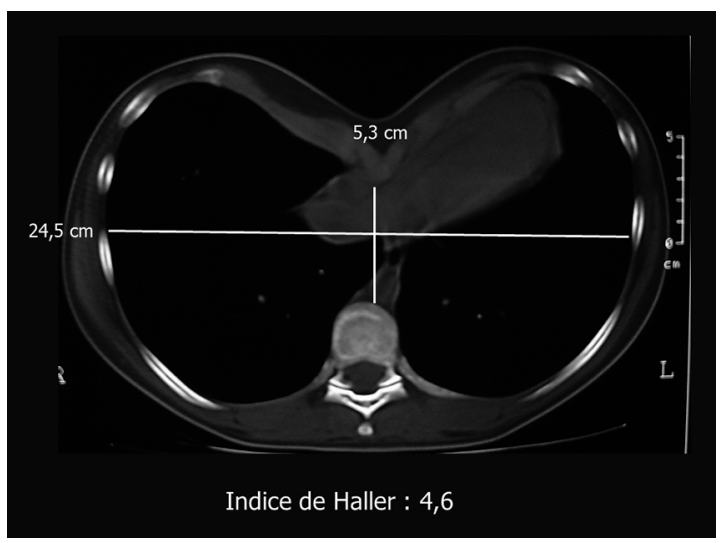

Figura 2. Tomografía Computada de tórax. Corte axial a nivel de apéndice xifoides del esternón, mostrando un marcado estrechamiento del diámetro ántero-posterior del tórax.

\section{Diagnóstico}

Pectus excavatum severo.

\section{Discusión}

El pectus excavatum (PE) corresponde a una malformación de la pared torácica caracterizada por una depresión del esternón, particularmente desde la porción media hacia distal, asociada a alteración de las articulaciones condro-esternales inferiores ${ }^{1-3}$. Es secundario a un desorden embriológico, por un defecto en la fusión entre las costillas y el esternón, lo que normalmente comienza alrededor del día 35 de gestación, continúa durante el resto de la gestación y termina con la osificación final durante la adolescencia ${ }^{4}$. Aunque en un tercio de los pacientes se identifica un patrón hereditario y existen otros miembros afectados en la familia, no se ha determinado un factor genético específico ${ }^{4,5}$.

Esta lesión representa el 75 a $90 \%$ del total de las malformaciones que afectan la pared del tórax ${ }^{1-4}$. La incidencia comunicada en la literatura es de 1/400 a 1/1.000 nacidos vivos y es 5 veces más frecuente en varones con respecto a las mujeres ${ }^{5}$.

Puede presentarse al nacer y aumentar progresivamente con la edad, pero con mayor frecuencia se hace clínicamente más evidente en el periodo de la adolescencia ${ }^{1-3,5}$. La regresión espontánea del defecto ha sido descrita, pero es poco frecuente y no debe esperarse después de los 6 años ${ }^{7}$.

Las manifestaciones clínicas son variables y dependen de la severidad del defecto de la pared y la morbilidad cardiopulmonar asociada. En los cuadros leves, por lo general la principal preocupación del paciente es el componente estético. En casos severos puede comprimir órganos torácicos y producir disnea, alteraciones cardíacas, intolerancia al ejercicio, dolor torácico, limitación restrictiva de la vía aérea, infecciones respiratorias frecuentes ${ }^{2,3}$.

Con mayor frecuencia el PE se presenta como un defecto único, pero hasta en un $20 \%$ puede asociarse a otras anormalidades esqueléticas, dentro de las cuales la más frecuente es la escoliosis ${ }^{8}$. Más raramente el PE puede ser una manifestación de enfermedades sistémicas neuromusculares y del tejido conectivo, particularmente Síndrome de Marfan, Síndrome de Loeys-Dietz, Síndrome de Ehler-Danlos y Osteogénesis imperfecta ${ }^{9,10}$. Esta relación ha hecho plantear una alteración de la síntesis del cartílago como posible factor causal. Se presume también que sería secundario a cambios en la mecánica ventilatoria cuando se asocia a enfermedades como la hernia diafragmática o atrofia espinal muscular tipo $1^{3}$.

De acuerdo con algunos autores ${ }^{3}$, ya en el siglo XVI aparecieron las primeras publicaciones alusivas al PE y su presentación clínica. Durante el s. XIX habría comenzado a vislumbrarse la predisposición familiar de esta deformidad, con la comunicación de casos clínicos repetidos dentro de una misma familia ${ }^{2,3}$. Inicialmente el tratamiento se limitaba a "aire fresco, ejercicios de respiración, actividades aeróbicas y presión lateral" y recién a principios del siglo pasado 
se practicaron las primeras cirugías torácicas, inicialmente con morbimortalidad significativa ${ }^{2}$.

La radiografía $(\mathrm{Rx})$ de tórax en proyecciones anteroposterior y lateral es necesaria en la evaluación del defecto y puede ser útil además en la búsqueda de escoliosis o enfermedad pulmonar concomitante.

Sin embargo, en casos moderados a severos o en aquellos donde existe alguna repercusión cardiopulmonar, el estudio indicado es la Tomografía Computada (TC) de tórax, que permite definir la magnitud de la depresión esternal y la repercusión sobre los órganos intratorácicos. Para esto se cuenta con el índice de Haller, que corresponde a la relación entre el diámetro transversal del tórax y la distancia entre el esternón y la columna vertebral en el punto de mayor depresión ${ }^{2}$. Este índice recibe su nombre en honor a Jack Haller, médico Radiólogo pediátrico pionero en esta área ${ }^{11}$. En general un índice $>3,25$ se considera como patológico.

Es recomendable realizar además ecocardiografía y estudio de función pulmonar.

El manejo del PE es generalmente quirúrgico, si se cumplen ciertas condiciones. A modo general se recomienda la cirugía cuando hay hundimiento moderado a severo, con un índice de Haller $>3,25$, progresión de la deformidad torácica, compresión de órganos torácicos, deficiente mecánica ventilatoria por limitación ventilatoria restrictiva, prolapso de válvula mitral o cualquier alteración cardiaca atribuible a una compresión de cavidades derechas. Sin embargo, el factor estético puede ser importante al momento de decidir la conducta.

Actualmente se prefieren los procedimientos mínimamente invasivos siendo la técnica de Nuss la más utilizada ${ }^{2,6}$, que consiste en la introducción de una barra metálica retroesternal, mediante videotoracoscopía.

\section{Bibliografía}

1. KELLY R E, LAWSON M L, PAIDAS C N, HRUBAN R H. Pectus excavatum in a 112-year autopsy series: anatomic findings and the effect on survival. J Ped Surg 2005; 40: 1275-8.

2. VARELA P. Pectus Excavatum. Historia y propuestas actuales para el estudio y tratamiento. Rev Med Clin Condes 2009; 20: 769-75.

3. KELLY K E. Pectus excavatum: historical background, clinical picture, preoperative evaluation and criteria for operation. Seminars in Pediatric Surgery 2008; 17: 18193.

4. ABDULlAH F, HARRIS J. Pectus Excavatum: More Than a Matter of Aesthetics. Pediatric Ann 2016; 45: e403-6.

5. FOKIN A A, STEUERWALD N M, AHRENS W A, ALLEN K E. Anatomical, histological, and genetic characteristics of congenital chest wall deformities. Semin Thorac Cardiovasc Surg 2009; 21: 44-57.

6. NUSS D, OBERMEYER R J, KELLY R E. Pectus excavatum from a pediatric surgeon's perspective. Ann Cardiothorac Surg 2016; 5: 493-500.

7. FONKALSRUD E W. A total of 912 open pectus excavatum repairs: changing trends, lessons learned: one surgeon's experience. World J Surg 2009; 33: 180-90.

8. HONG J Y, SUH S W, PARK H J, KIM Y H, PARK J H, PARK S Y. Correlation of adolescent idiopathic scoliosis and pectus excavatum. J Pediatr Orthop 2011; 31: $870-4$

9. SPONSELLER P D, ERKULA G, SKOLASKY R L, VENUTI K D, DIETZ H C 3rd. Improving clinical recognition of Marfan syndrome. J Bone Joint Surg 2010; 92:1868-1875.

10. ERKULA G, SPONSELLER P D, PAULSEN L C, OSWALD G L, LOEYS B L, DIETZ H C. Musculoskeletal findings of Loeys-Dietz syndrome. J Bone Joint Surg 2010; 92: 1876-83.

11. SLOVIS T L, BERDON W E. In Memoriam: Jack O. Haller, MD. Radiology 2014; 233: 939.

Correspondencia a:

Dr. Cristián García B.

Departamento de Radiología, Facultad de Medicina,

Pontificia Universidad Católica de Chile.

Email: cgarciab@uc.cl 